\title{
THE CHALLENGE OF TEACHING LARGE CLASSES IN HIGHER EDUCATION IN SOUTH AFRICA
}

\section{A BATTLE TO BE WAGED OUTSIDE THE CLASSROOM}

Jeff Jawitz

\section{INTRODUCTION}

The main focus of my work as an educational development practitioner is to help strengthen the quality of teaching in higher education. My aim is to work with colleagues to 'get it right' and by that I mean getting it right for all role players, namely students, lecturers and institutions. For students, this means supporting them in their learning and engagement with disciplines and professions; for lecturers, enhancing our sense of integrity and fulfilment as teachers and academics; and for institutions, developing systems and programmes for delivering quality educational experiences in South Africa at the start of the 21 st century.

From 2008 to 2103, I headed the 'Large Classes Project', an initiative aimed at improving student learning in large-class contexts involving case studies at four institutions of higher learning.' The project was initiated because of widespread concern about the challenge of providing high-quality learning experiences for students attending such classes.

In this chapter, I suggest that large classes offer unique opportunities for delivering the quality learning experience we wish for our students. However, taking advantage of these opportunities require significant planning, support and expertise. I also discuss current practices that undermine the efforts of individual lecturers to achieve effective learning in their classes. Much of what is presented here is based on my experience of working with the institutions involved in the Large Classes Project.

\section{HOW LARGE IS ‘LARGE'?}

As I made my way to the front of the lecture hall one day to do a presentation on largeclass teaching, I was cornered by an earnest young man who demanded to know,

The University of Cape Town (UCT), the University of the Western Cape (UWC), the University of Johannesburg (UJ), and the University of Fort Hare (UFH). 
"How big is a large class?" There appeared to be some disagreement among his colleagues as to what should rightfully be classified as a 'large class'. It was also not the first time I had been approached with this question. I have never really understood the fascination with the actual number that signals the transition to a large-class context. Clearly, it depends on various factors, but any class that lacks sufficient basic resources venues, seats, computers, drawing boards and so on is too big. What is big, or too big, also varies from discipline to discipline. For example, disciplines such as music, dance, art and architectural design require one-to-one modes of teaching, while some health sciences programmes involve practical training in clinical settings and engagement with patients, which places constraints on the numbers of students that can be accommodated at a time.

In trying to get a general idea of how big a large class is, it also does not help to turn to the educational research literature. While there has been substantial research regarding the significance of class size in relation to effective teaching in primary and secondary schooling (Benbow, Mizrachi, Oliver \& Said-Moshiro 2007), very few studies have been conducted in higher education (Toth \& Montagna 2002). A web search using the keywords 'teaching large classes' reveals a number of teaching guides that have been published, many of them online, to provide advice and support for lecturers teaching large classes, ${ }^{2}$ but none of them draws specifically on research related to teaching large classes.

Given the lack of a research-based benchmark for defining a large class, I have arbitrarily chosen a hundred students as my threshold number for a large class. While this figure does not take into account the fact that even small classes can become 'large' when there are resource constraints, it provides an indicator to use in the discussion that follows.

\section{VERY LARGE CLASSES}

I would like to make the distinction between large classes that can be accommodated in a single venue and what I will refer to as 'very large classes', where room size constraints demand that the class be divided and taught separately. This can take the form of repeat lectures, where the class is repeated several times, either by the same lecturer or by several different lecturers; or simulcast lectures, where the class is presented by a single lecturer and simulcast (broadcast simultaneously) to different 'overflow' venues (Exeter, Ameratunga, Ratima, Morton, Dickson, Hsu \& Jackson 2010). It is one thing to be able to deliver an effective teaching experience in one large room full of students; it is another to manage the delivery of an effective teaching experience across several venues or time slots involving several large rooms full of students.

\footnotetext{
See, for example, Preparing to teach the large lecture course (http://teaching.berkeley.edu/ bgd/largelecture.html) and Teaching large classes (http://serc.carleton.edu/NAGTWork shops/earlycareer/teaching/LargeClasses.html).
} 
The most astonishing example of a very large class that I have come across in South Africa has been the Introduction to Business Management course at the University of Johannesburg (UJ), which registers between 3,500 and 4,000 students each year. During the past few years, I have had the privilege of working with the convenor of this course, who uses the repeat lecture system and arranges for each lecture to be repeated six times, most of them in a venue that can accommodate about 700 students.

The very large class phenomenon is generally associated with first year-classes in particular disciplines and faculties, such as commerce. However, an analysis of very large classes at the University of Cape Town (UCT) and the University of the Witwatersrand (Wits) reveals some interesting institutional differences with regard to disciplines.

In 2011 , the largest venue at UCT could seat 458 students. Thirty-six undergraduate courses had a higher number of registered students than this. These courses were spread across five faculties, with the majority concentrated in commerce (Table 9.1). ${ }^{3}$ At the same time, the largest lecture hall at Wits could accommodate 450 students. Unlike at UCT, the highest concentrations of very large classes at Wits were to be found in the humanities and law faculties (Table 9.2). At both institutions, many of the large classes offered by the science and law faculties are service courses for commerce and engineering students, and do not form part of the curriculum leading to majors in the scientific and legal disciplines, which has significant consequences in terms of who ends up teaching them.

TABLE 9.1 Disciplinary spread of courses with more than 458 students at UCT (2011)

\begin{tabular}{|l|l|l|l|}
\hline Commerce & Science & Law & Humanities \\
\hline - Macroeconomics I \& II & 5 Courses & 4 Courses & 7 Courses \\
\hline - Microeconomics I \& II & - Statistics I & - Business & - Introduction \\
- Financial Accounting & - Mathematics I & Law I (x 2) & to Psychology \\
- Financial Reporting I, II \& III & - Business & - Business & - Introduction \\
- Information Systems I & Statistics & Law II & to Sociology \\
- Finance I & - Mathematics & - Company & - Introduction \\
- Auditing I & for Engineers & Law & to Politics \\
- Evidence-based Management & - Vector & & - English \\
- Cooperation and Competition & Calculus for & & Literary \\
- Control of Financial Information Systems & & & - Individual \& \\
- IT in Business & & & Society \\
- Management Accounting I \& II & & & - Business \\
- Advanced Macro and Micro Economics & & & Ethics (x 2) \\
- Taxation II & & & \\
- Marketing I & & &
\end{tabular}

3 Data for Tables 9.1 , 9.2 and 9.3 were obtained directly from the respective units responsible for student registration at the universities concerned. 
TABLE 9.2 Disciplinary spread of courses with more than 450 students at Wits (2011)

\begin{tabular}{|c|c|c|c|}
\hline Commerce & Science & Law & Humanities \\
\hline 9 Courses & 10 Courses & 10 Courses & 16 Courses \\
\hline $\begin{array}{l}\text { - Accounting I } \\
\text { - Economics I } \\
\text { - Business } \\
\text { Statistics I } \\
\text { - Business } \\
\text { Accounting I } \\
\text { - Business Ethics II } \\
\text { - Taxation II \& III } \\
\text { - Management } \\
\text { Accounting and } \\
\text { Finance II \& III }\end{array}$ & $\begin{aligned} & \text { - } \text { Computational } \\
& \text { - } \text { Mathematics I } \\
& \text { - Mechanics I } \\
& \text { - Physics I } \\
& \text { - Chemistry I } \\
& \text { - Chemistry I } \\
& \text { (Eng) } \\
& \text { - Calculus I } \\
& \text { - Algebra I } \\
& \text { - Introduction to } \\
& \text { Life Sciences } \\
& \text { - Ancillary } \\
& \text { Mathematics \& } \\
& \text { Stats I }\end{aligned}$ & $\begin{array}{l}\text { - } \text { Commercial } \\
\text { - } \text { Business } \\
\text { Enterprise Law } \\
\text { - Mercantile Law } \\
\text { - Customary Law } \\
\text { - Foundations of } \\
\text { SA Law } \\
\text { - Family Law and } \\
\text { - Law of Persons } \\
\text { - Introduction to } \\
\text { Constitutional Law } \\
\text { - Introduction to Law } \\
\text { - Criminal Law } \\
\text { - Law of Contracts }\end{array}$ & $\begin{array}{l}\text { - } \text { Basic Principles of Individual } \\
\text { - } \text { - Studies in Education B } \\
\text { - Life Studies in Education } \\
\text { - Mathematical Concepts in } \\
\text { Teaching } \\
\text { - Education I } \\
\text { - Mathematical Routes } \\
\text { - New Literacies for Teachers } \\
\text { - Cognition and Social } \\
\text { - Psychology II } \\
\text { - Personal and Developmental } \\
\text { - Introduction to Psychology I } \\
\text { - English Literature in Context I } \\
\text { - Global Literature and Film I } \\
\text { - Introduction to Anthropology } \\
\text { - Psychology RDA II } \\
\text { - Teaching Experience I \& II }\end{array}$ \\
\hline
\end{tabular}

\section{LARGE CLASSES OFFER SPECIAL OPPORTUNITIES}

The view that large-class lectures in higher education are 'bad' and should be avoided if possible is a dominant one that needs to be challenged. Not enough attention has been paid to the advantages and special opportunities that exist in working with large classes, and the lecture as a particular mode of teaching can play an important role as one of a set of learning experiences that we can design for our students. We need to understand its strengths and limitations, and exploit the possibilities that it holds.

Large lectures are particularly suited to providing an overview of the discipline and the concepts and phenomena that students are required to understand. They are also well suited to providing experiences that motivate students by making the link between course material, their own lives, and the challenges faced by the broader society. We can learn a great deal from taking note of how motivational speakers work with large audiences. One aspect is the skilful way in which they master techniques to engage large numbers of people at the same time. A second aspect is their firm sense of their own identity, their confidence in their authority, their credibility, and who they are presenting themselves to be. Both of these are areas in which most academics, particularly novices, require substantial support.

The most significant advantages offered by large classes lie in exploiting the social dimension in the classroom and economies of scale. 


\section{Exploiting the social dimension}

Anyone who has been to a soccer match, an orchestral recital or a rock concert hopes for the place to be packed. Large numbers of people gathered in one place exude energy, which comes from a collective appreciation and enjoyment of something significant that is either already in progress or about to happen. Large classes provide us with the dual opportunity to construct our lectures as important, not-to-be-missed events, and to draw on the energy and emotion associated with crowds to achieve the goal of facilitating significant learning. A participant in one of the case studies I referred to in the introduction had this to say about large classes:

I love large classes [...] because [...] you can get that group dynamic working for you. The excitement is just multiplied exponentially if you have many people involved in it.

(Personal interview 2011)

This view was also articulated in a little known paper by Wolfman about the 'bright side' of teaching large classes, in which he calls on lecturers to "turn this crowd atmosphere to pedagogical use" (2002:2). We need to find ways to draw on the traditions of lecturing, performance, motivational speaking and dramatic production so as to create an experience that enables learning for large numbers of students. By cultivating a sense of belonging in a large community of learners, one is feeding into each student's need to be part of something significant. Our course can provide the vehicle for a journey of discovery, which might in fact produce a unique path for each student, as well as significant elements of shared experience.

Large classes also offer the opportunity to exploit a more visible level of diversity among students in terms of gender, race and class than often occurs in small classes. In a large class, there is a greater likelihood of significant clusters of students with a wide range of backgrounds, experiences, learning styles, or problem-solving abilities. These clusters are a valuable resource for the lecturer. For example, student registrations in many of the science, engineering and technology disciplines still suffer from a gendered imbalance, with significantly more male than female students enrolling in these courses. Using interactive classroom techniques that aim to incorporate the female voice tend to yield less effective results when one is working with three female students in a class of thirty than, say, thirty female students in a class of 300 . However, the potential of this diversity can only be exploited if the lecturer has the necessary experience and skill to know how to take advantage of it.

\section{Exploiting economies of scale}

Having a single lecturer simultaneously provide a learning experience to a large number of students in (or from) a single venue can be very resource-efficient, as it represents significant savings in terms of both costs and time and effort spent in the preparation of lectures, communication with students, the preparation and distribution of information and resource documents, and the setting and distribution of tasks and assignments. 


\section{PART THREE • SUPPORTING LARGE-CLASS TEACHING}

Investment in new technologies, including multimedia presentation technology and learning management systems such as Blackboard, can provide significant leaning experiences to large numbers of students at the same time. Podcasting and video recording technologies allow students to review what happened in class, while the use of mobile response technology, such as clickers, can facilitate interactive learning during lectures. In addition, setting tasks and assessments for a single large class, and sharing the marking of these tasks among support staff, is easier to manage and control than having a lecturer set and mark different tasks and assignments with different criteria across several smaller courses. The number of students served by a large course, which translates into significant income earned by the department, should justify the expenditure on the technology and additional support staff required to exploit these opportunities.

\section{SO, WHAT IS THE PROBLEM?}

Well, there are several fundamental ones. While large classes form a significant part of the first-year experience of most students at South African higher education institutions, relatively few academics are involved in large-class teaching. This is because courses with more than 100 or 200 registered students constitute only a small portion of the total courses offered at our universities, as can be seen from Table 9.3.

At three of the institutions surveyed, less than one-third of undergraduate (UG) courses had more than 100 students enrolled in 2010/11, while less than sixteen per cent of all UG courses offered at all four universities had more than 200 students. When postgraduate courses at these institutions are added to the picture, the proportion of classes with 100 students or more reduces even further. For example, at Wits, only eleven per cent of all courses, including postgraduate ones, involved classes of more than 100 students.

Although several of these large classes might involve more than one lecturer, the evidence suggests that the majority of academics at these institutions do not participate in the teaching or management of large classes, and it is therefore not of direct concern to them. Anyone striving to get higher education institutions to take the issue of largeclass teaching seriously should bear this in mind.

TABLE 9.3 Proportion of large UG courses at selected South African universities

\begin{tabular}{|l|c|c|}
\hline \multicolumn{1}{|c|}{ Institution } & $\begin{array}{c}\text { UG courses with } \\
>100 \text { students }\end{array}$ & $\begin{array}{c}\text { UG courses with } \\
>200 \text { students }\end{array}$ \\
\hline University of Johannesburg (2010) & $37 \%$ & $15 \%$ \\
\hline University of Cape Town (2011) & $25 \%$ & $10 \%$ \\
\hline University of Pretoria (2010) & $28 \%$ & $16 \%$ \\
\hline University of the Witwatersrand (2011) & $24 \%$ & $12 \%$ \\
\hline
\end{tabular}


However, the issue is not just that only a minority of academics are directly involved in large-class teaching, but also with who this minority is. The lecturers assigned to teach these classes are often new or part-time lecturers (and sometimes even postgraduate students). These are the colleagues who cannot say 'no', while many of the senior staff and experienced teachers move on to greener pastures, teaching postgraduate courses and selected senior undergraduate courses that feed directly into their efforts to attract postgraduate students to their disciplines and research groups, and generally shunning large service courses, because these courses do not serve their purpose of developing new scholars in their own discipline.

How and why has this situation been allowed to develop? The main reason is the widely held view in higher education that teaching is easy. Generally speaking, lecturers are appointed with no proven teaching ability, and are sent into the classroom with very little support, if any. The notion of teaching being easy is based on a particular understanding of what teaching in higher education involves, with the dominant discourse holding that it is about communicating key disciplinary concepts to students. Thus, new academics spend hours preparing slides and other material, and then arrive at the venue to deliver the lecture that they have so painstakingly constructed.

This conceptualisation of teaching views content as having to be 'taught' and the lecturer as doing the work of 'teaching', while 'learning' the material is the student's responsibility. With this view in mind, it is understandable that the demand for support from academic staff developers centre on techniques and tools for delivering content. PowerPoint is currently one of the most favoured allies in this task: dim the lights, switch on the presentation, and drill home your message, one bullet at a time! What students actually do during this time is not the lecturer's primary concern.

However, this approach to teaching has been challenged from several quarters, probably most eloquently by Paul Ramsden (1992), who argues that good teaching is about facilitating high-quality student learning. The shift in focus from delivering content to facilitating student learning is a fundamental one and underpins the complex nature of teaching, as it requires an understanding of both the disciplinary material and everything that enables or inhibits learning. Therefore, one might argue that teaching large classes (or any class for that matter) is only difficult if facilitating student learning is one's main objective. However, if this is the primary goal, then the challenges associated with it are hardly trivial. In the context of large classes, this kind of teaching requires experienced and expert lecturers and adequate access to resources in order to achieve several things in (and out of) the classroom, namely:

- to establish authority and credibility among students;

- to meet each individual student's learning needs;

- to prevent students from feeling insignificant, invisible or alienated;

- to take advantage of the social dimension in the class; 


\section{PART THREE • SUPPORTING LARGE-CLASS TEACHING}

- to take advantage of the economies of scale offered by the course;

- to overcome institutional limitations, particularly resource constraints; and

- to manage and administer the course.

In addition, the South African lecture room, with its particular mix of race, gender and class, also presents other challenges associated specifically with teaching in post-conflict societies. In such environments, classrooms are often "deeply divided places where contending histories and rival lived experiences come [...] into the same pedagogical space" (Jansen 2009:258).

This is precisely why, if higher education institutions are serious about improving student learning - particularly in first-year courses, where most large classes occur - they should assign their most skilled and effective lecturers to teach large classes alongside newer academics, so that they may be mentored with regard to facilitating student learning in their given discipline.

\section{CAN IT BE DONE?}

Anyone who doubts that effective learning and lecturing can take place in large-class contexts should watch Harvard University's Michael Sandel lecturing to 1,500 students in the Sanders Theatre (Sandel 2005). Forget for a moment that this lecture series is being professionally captured on film and that some aspects are clearly choreographed for the camera. What is Sandel doing that makes his lecture so enthralling?

This relatively nondescript, middle-aged man in a grey suit is the antithesis of a flamboyant performer. He delivers his presentation in a clear and calculated manner, without any bursts of passion or enthusiasm that one might consider necessary to hold the attention of such a huge audience. What is evident from watching him is his skilful use of a range of teaching methods to engage with and involve his audience in the content of his lecture. His use of active learning techniques from getting students to raise their hands to inviting them to put forward their views is a convincing refutation of the claim by many lecturers that this cannot be done in large classes.

Sandel's lecture is carefully structured, beginning with a problem, a dilemma, a choice to be made. He involves his students and encourages them to articulate their views using a team of teaching assistants with roaming microphones. The simply use of this basic technology brings their voice clearly into the classroom. He also invites students to develop arguments for each choice in order to elaborate the various elements of the material that he wishes to focus on. After about fifteen minutes, he shifts into formal lecture mode, drawing on the students' contributions to summarise and illustrate the theories he wishes to explain and making limited but calculated use of images on a digital overhead projector.

There might be some who would argue that the nature of Sandel's discipline, philosophy, lends itself to such interesting and active student engagement. However, even if the search for good case studies or stories that can capture the interest of students is 
challenging, every discipline needs to be mined for them. Financial crises, political and ethical scandals, technological challenges and disasters, controversies over gender in athletics, plagiarism in research, legal challenges over intellectual property these from the substance of our daily newspapers and television news programmes, and each one could supply dozens of lectures with material across a range of disciplines. Some of our colleagues already make use of them, but they are the minority. The main reason why most academics do not construct their lectures in the way that Sandel does, is that they do not have the expertise required to do so. A new academic at UCT articulated the problem like this:

The challenge in my teaching is really how to deliver an exciting and entertaining lecture, where everybody participates, without losing focus and credibility [...] Sometimes, only a subset of students engage in a discussion and you wonder whether the others are just absorbent capturers of the facts, or are just plain bored. My challenge is how do I capture these dormant students and take them with me on a journey? How do I 'speak' to these students? How dol 'open them up' without embarrassing them in front of the class? How do I make my subject passionate?

(Personal interview 2009)

\section{RESOURCING}

One of the big ironies in higher education is that large classes in certain disciplines are often justified in terms of economies of scale in order to cross-subsidise other disciplines or postgraduate studies, which require more intensive small group tuition. Clearly, there is a good case to be made for this in any institution that wishes to offer a balanced programme across a range of disciplines. However, care should be taken that this is not done in a way that leads to an effective under-resourcing of large-class teaching in order to balance the books, thereby undermining efforts to produce quality learning experiences for students attending those large classes. While it is admissible to exploit economies of scale in the ways referred to above, enabling effective learning opportunities for all students in a large class requires the provision of resources that complement what the large-class lecture has to offer.

A basic list of what needs to be in place includes appropriate professional development opportunities in teaching for all lecturers, and the constitution of sufficiently resourced course teams with the necessary expertise, including senior and junior teaching staff, tutors and administrative staff; appropriately equipped and designed venues; welldesigned learning resources, such as workbooks, handouts, videos, etc; and access to and appropriate use of online and web-based learning management systems.

\section{THE BATTLE TO BE WAGED}

The main point I wish to make is this: if proper attention is not paid to the fact that teaching to facilitate student learning is a complex activity, which requires relevant educational expertise and adequate resourcing, efforts by individual lecturers to 


\section{PART THREE • SUPPORTING LARGE-CLASS TEACHING}

improve teaching in their large classes are doomed to fail before they even enter the classroom. The chips are just stacked too heavily against them.

The failure by most higher education institutions to acknowledge the level of expertise required to facilitate student learning and to provide support to all academics to develop this expertise is the most significant obstacle to effective teaching, irrespective of the size of the class. If the notion that teaching is easy, and that anyone can learn how to teach by simply going into the classroom and just doing it, is allowed to persist, generations of students will continue to be condemned to hours of mediocre, if not poor, teaching and lecturers to a sense of frustration and general lack of fulfilment in the classroom.

The general practice of assigning the most junior and often the least experienced, new lecturers to teach large first-year classes without training or support is a recipe for disaster and perpetuates a situation where academic staff strive to work their way out of undergraduate teaching and hand these classes over to colleagues more junior than themselves as they achieve promotion. The assignment of staff who are lower down in the academic pecking order to teach large classes means that not only are they unlikely to have the experience and expertise to design significant and successful learning experiences, but they also do not have the necessary clout to negotiate for the resources required to give large-class teaching a chance of success. Departmental and faculty resources are more likely to be channelled to support prestigious postgraduate programmes.

Finally, given that the majority of academics particularly those with seniority and power are not involved in the relatively small proportion of courses with more than a hundred students, the issue of improving teaching in large classes does not draw significant support when it is put on the departmental or institutional agenda.

\section{CONCLUSION: WHAT IS TO BE DONE?}

In order for efforts to improve teaching in large classes to have any chance of success, there must be a significant change in institutional attitude and practices towards the development of teaching among academics, and due recognition of the amount of expertise needed to make a success of facilitating learning in large classes. The responsibility for teaching large classes needs to be in the hands of senior academics who have a proven record of success in their own teaching development and who are able to mentor junior and less experienced staff in teaching teams assigned to large classes. These teams must be sufficiently well resourced to take advantage of the potential of large-class lectures, alongside other learning activities, to excite, motivate and inspire students to pursue the discipline. Without such a system in place, our students will have to continue suffering our attempts at waging a losing battle, while our colleagues will continue to demonise large classes as being part of the problem of rather than part of the solution to providing effective learning experiences. 